\title{
Design and Research on the insulation system of high altitude live working vehicle
}

\author{
Yinbo $\mathrm{Du}^{1, \mathrm{a}}$, Li $\operatorname{Tan}^{1, \mathrm{~b}}$, Lei Xia ${ }^{1, \mathrm{~b}}$, Hong Xiang ${ }^{1, \mathrm{~b}}$, Dahong Wang ${ }^{2, \mathrm{c}}$ \\ ${ }^{1}$ State Grid Chongqing Electric Power CO. Electric Power Research Institute, Chongqing 404100; \\ ${ }^{2}$ Shenzhen Institute of Advanced Smart Technology, Shenzhen 518055 \\ a970349923@qq.com, ${ }^{\mathrm{b}} 1341775116 @ q q . c o m,{ }^{\mathrm{c}}$ bauswang@126.com
}

Keywords: insulating arm; insulating work bucket; glass fiber reinforced plastic

\begin{abstract}
The aerial electric operation vehicle is to meet $10 \mathrm{kV}$ and the following live line maintenance work. The insulation system is basically equipped with electric operation vehicle, equipped with one of the most important at the same time. Insulation system including insulation and isolation insulation protection arm, insulation bucket and electrical system. Arm insulation and insulation bucket is made of composite insulation materials, glass steel, insulated and can ensure the structural strength and stiffness; electrical insulation is in addition to the basic wire insulation to prevent breakdown and short circuit and insulation work of fighting the operating system must also use isolation transformer power supply to prevent high pressure through the main power supply line and earth conduction, to guarantee the insulation level.
\end{abstract}

\section{Introduction}

Aerial electric operation vehicle as a special engineering vehicle, its particularity lies in: (1) manned high-altitude operations, the operation of the safety requirements will be higher than the general engineering vehicle, the so-called "high security"; (2) is the construction site of the "unstructured", namely the working environment can not be predict and changeable, therefore has the high adaptability to the environment; (3) it is often used for the repair work, and for the outdoor environment or field work, working condition is poor, so requires a work of "high efficiency"; (4) is charged for the industry environment, and many high above $10 \mathrm{kV}$. So the insulation level is higher, which is high insulation reliability".

\section{2. insulation system design}

The insulation system rely on insulating materials, high electric operation vehicle insulation and insulation work bucket arm made of glass fiber reinforced epoxy resin material is made of glass reinforced plastic material[1,2]. The fiberglass winding made of rectangular cross section structure, with light weight, high mechanical strength, good electrical insulation, strong hydrophobicity and other advantages, in live working for the human body to provide relatively between the insulation protection. Insulating arm and insulation work to fight the glass steel mold making, double-sided glass steel mold molding, both inside and outside the smooth surface, no burr, no bubbles, compactness. The main parameters are shown in table 1 . 
Tab.1 Main Parameters of Insulation Material

\begin{tabular}{cc}
\hline Parameter term & parameter values \\
\hline density $/ \mathrm{kg} \cdot \mathrm{m}-3$ & 1.73 \\
tensile strength $/ \mathrm{Mpa}$ & 290.77 \\
bending strength /Mpa & 330.06 \\
Elastic modulus /Gpa & $70 \sim 72$ \\
Poisson ratio & $0.22 \sim 0.33$ \\
Breakdown voltage of & $\geqslant 15$ \\
parallel layer / $\mathrm{kV}$ & $4.7 \sim 5.2$ \\
Dielectric constant &
\end{tabular}

\section{1 insulated arm}

The insulation arm is composed of a glass steel arm and a steel metal head, which is directly and quickly, and the mechanical performance is reliable. The insulating arm is a telescopic arm, which is driven by a telescopic oil cylinder, and the upper and lower sliding of the upper folding arm. The rear end of the insulated arm and the front end of the telescopic arm are provided with a MC wear-resistant nylon (or PE nylon) slide block. Due to the large bearing force[3,4], and no grease or graphite lubrication and other measures, the slider is a consumable material, need to be replaced regularly.

The front end of the insulation arm is welded with Q235B material, and the mounting hole is used to ensure the coaxial degree. Main parameters see table 2.

Tab.2 Main Parameters of Q235

\begin{tabular}{cc}
\hline Parameter term & parameter values \\
\hline density $/ \mathrm{kg} \cdot \mathrm{m}-3$ & 7.85 \\
tensile strength $/ \mathrm{Mpa}$ & $375 \sim 460$ \\
bending strength $/ \mathrm{Mpa}$ & 235 \\
Elastic modulus $/ \mathrm{Gpa}$ & $200 \sim 210$ \\
Poisson ratio & $0.25 \sim 0.33$ \\
elongation $/ \delta 5 / \%$ & $\geq 26(\mathrm{a} \leq 16 \mathrm{~mm})$ \\
\hline
\end{tabular}

Note: $\mathrm{a}$ is the thickness or diameter of the material.

Through the comparison, it is found that the glass fiber reinforced plastic and Q235 are close to the strength and Poisson's ratio, but why the end of the non Q235 metal parts should be used. In addition to the Q235 in the welding performance and processing molding is relatively dominant, one of the most important reason is the elastic modulus.

In the elastic phase, stress is proportional to strain, after adding a constant to the equation, which is the modulus of elasticity is a constant value, only with the relevant materials.

$$
\sigma=\mathrm{E} \varepsilon
$$

Different materials, when the stress is constant, elastic modulus E, the strain becomes smaller; the elastic modulus $\mathrm{E}$ of small strain is bigger. This shows that $\mathrm{E}$ is a parameter that reflects the size of the material's resistance to deformation. If the cross-sectional area of $\mathrm{F}$ is also taken into account, then EF also known as tensile stiffness. Stiffness is more able to explain the ability of the component to resist tensile deformation. So taking into account the end of the insulation arm need to install insulation working bucket and leveling cylinder and other important components, so it must be used to resist the deformation ability of stronger, better welding performance of Q235 material[5].

The insulating arm in the initial state without elongation, a glass steel arm is not fully retracted. This is in order to work at low altitude, the insulation arm does not extend the case, to ensure the effective insulation length of $400 \mathrm{~mm}$, to ensure the insulation level. As shown in figure 1 . 


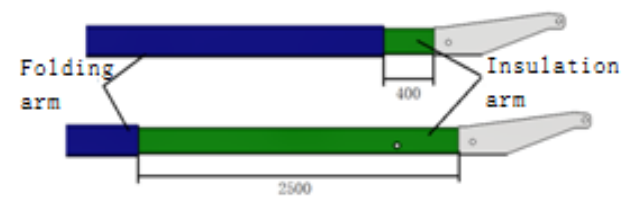

\section{2 insulation work}

Fig1. elongation and shrinkage of insulating arms

The insulation work bucket is made of glass fiber reinforced plastic, which comprises an insulating bucket, a bottom reinforcing rib, a side reinforcing rib, an operating table protective cover and a lifting guide groove. Insulated bucket according to two working space of about 1.2 meters design, load according to the weight of a person and the necessary tool weight together $200 \mathrm{~kg}$ design, wall thickness $6 \mathrm{~mm}$. In order to meet the safety factor of 2 times, the insulation bucket must be strengthened with the strengthening rib. Bottom rib is made of glass steel is wound into a rectangular or tapered, $4 \mathrm{~mm}$ thickness, lateral ribs in order to ensure the overall strengthening effect, by mold making into an L shape. The lifting guide groove is attached on the side reinforcement to ensure that the whole force is in good condition. As shown in figure 2

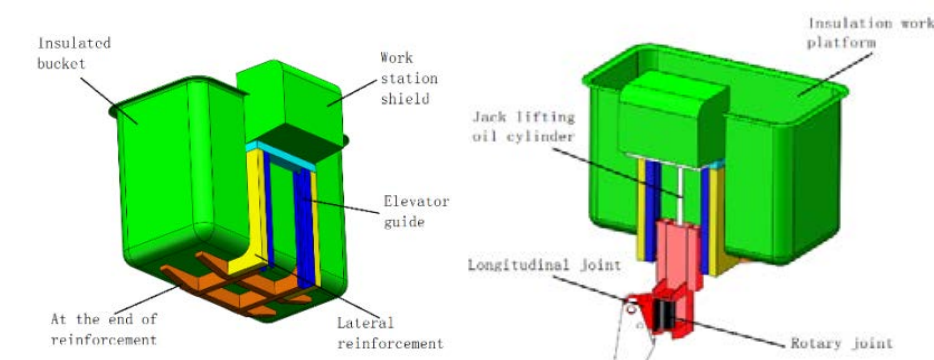

Figure 2.Insulating bucket and Insulation working bucket movement mode

\section{3. mechanical property analysis}

Using workbench ANSYS analysis of the insulation arm, using the limit conditions, that is, the longest arm of the insulation arm, the maximum level of stress:

(1) the results of the analysis, the maximum stress $216 \mathrm{MPa}<290 \mathrm{MPa}$, the safety factor $290 / 216=1.34$, the most extreme end of the insulation arm. As shown in figure3

(2) The results of the analysis, the maximum displacement of $41.6 \mathrm{~mm}$, located at the end of. As shown in figure 3:

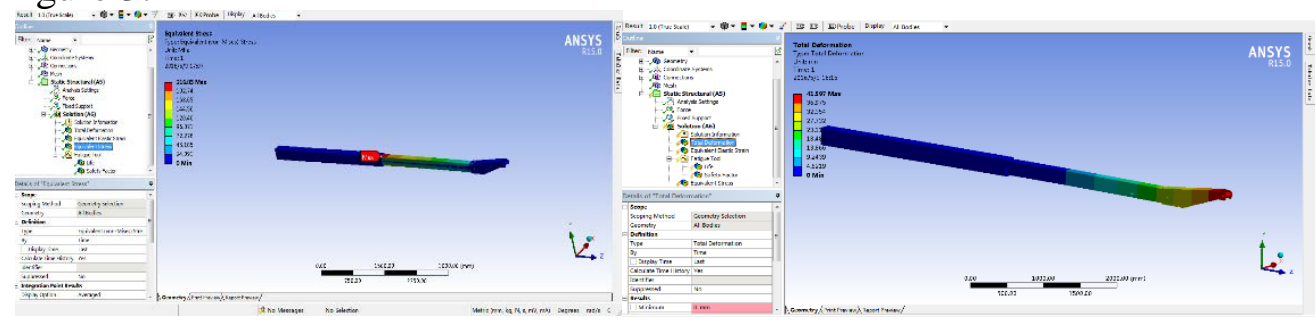

Fig 3 Stress cloudand Displacement contour

\section{4. conclusions}

By means of analysis and experiment, the strength, stiffness and safety factor of the insulation system all meet the established requirements, and the insulation level is in accordance with the relevant standards. Although the current maximum pressure design is only $10 \mathrm{kV}$, but I believe that with the successful design experience, the future will move towards a higher voltage, as soon as possible to catch up with the level of developed countries. 


\section{Reference}

[1] Zhang Hua, Huo Yulan. China's development and Prospect of aerial vehicle industry. construction machinery[J], 2009

[2] Ming Hui Liu, Shubo, he Ming Deng, Chen Ming Li, Li Jun ye, Ke Rui.66kV under AC transmission line phase conductor insulation bucket arm car charged operation. Hydroelectric energy science[J], by 2015.

[3] Zhao Yuliang, the system research on insulation hot line robot, "microcomputer and application" in 2012 thirty-first volume nineteenth.

[4] Cai Junyu, Li Tianyou, Tang Chuanping. The insulation bucket arm vehicle in distribution power supply electrical application of [J]. operation in 2015.

[5] Beijing construction machinery research, Hangzhou Aichi Engineering Vehicle Co., Ltd., Hangzhou race send high-altitude operation Car Co., Ltd.,. Aerial vehicle (GB / T 9465-2008). In Beijing: Standards Press of China, 2008. 